\title{
Factual power loss reduction by enriched black hole algorithm
}

\author{
Kanagasabai Lenin \\ Department of EEE, Prasad V. Potluri Siddhartha Institute of Technology, \\ Kanuru, Vijayawada, Andhra Pradesh, India
}

\begin{tabular}{l}
\hline \hline Article Info \\
\hline Article history: \\
Received Jan 9, 2020 \\
Revised Feb 20, 2020 \\
Accepted Mar 20, 2020 \\
\hline
\end{tabular}

Keywords:

Enriched black hole Optimal reactive power Transmission loss

\begin{abstract}
This paper presents enriched black hole algorithm (EBHA) for solving optimal reactive power problem. In this work black hole algorithm based on membrane computing is projected. In black hole algorithm evolution of the population is through pushing the candidates in the course of the most excellent candidate in iterations and black hole which swap with those in the search space. Membrane computing is also branded as P system and it has multisets of objects with evolution rules in the membrane structure. Membrane structure is alike ingrained tree of section that demarcate the areas, and root is labelled as skin. Chemical substances (multisets of objects) are there inside the section (membranes) of a cell and the chemical reactions (evolution rules) that take place within the cell. Proposed enriched black hole algorithm (EBHA) has been evaluated in IEEE 14,300 bus test system. Loss reduction achieved.
\end{abstract}

This is an open access article under the $\underline{C C B Y-S A}$ license.

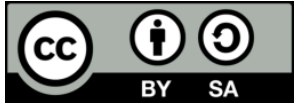

\section{Corresponding Author:}

Kanagasabai Lenin

Department of EEE

Prasad V. Potluri Siddhartha Institute of Technology

Kanuru, Vijayawada, Andhra Pradesh, India

Email: gklenin@gmail.com

\section{INTRODUCTION}

Many methodologies and algorithms [1-16] have been applied to solve the Real power loss reduction problem. In this paper, enriched black hole algorithm (EBHA) has been applied to solve the problem. In this work black hole algorithm based on membrane computing is projected. In Black hole algorithm, evolution of the population is through pushing the candidates in the course of the most excellent candidate in iterations and black hole which swap with those in the search space. Excellent candidate amongst all the candidates in iterations is chosen as a black hole and remaining candidates structured as the standard stars. From the structure of the biological cell's membrane computing is planned by conceptual calculation of model from the hierarchy of the cells. Membrane computing is also branded as $\mathrm{P}$ system and it has multisets of objects with evolution rules in the membrane structure. Membrane structure is alike ingrained tree of section that demarcate the areas, and root is labelled as skin. Chemical substances (multisets of objects) are there inside the section (membranes) of a cell and the chemical reactions (evolution rules) that take place within the cell. Proposed enriched black hole algorithm (EBHA) validated in IEEE 14,300 bus system. Power loss reduction achieved.

\section{RESEARCH METHOD}

Objective function of the problem is;

$$
\mathrm{F}=\mathrm{P}_{\mathrm{L}}=\sum_{\mathrm{k} \in \mathrm{Nbr}} \mathrm{g}_{\mathrm{k}}\left(\mathrm{V}_{\mathrm{i}}^{2}+\mathrm{V}_{\mathrm{j}}^{2}-2 \mathrm{~V}_{\mathrm{i}} \mathrm{V}_{\mathrm{j}} \cos \theta_{\mathrm{ij}}\right)
$$




$$
\begin{aligned}
& \mathrm{F}=\mathrm{P}_{\mathrm{L}}+\omega_{\mathrm{v}} \times \text { VoltageDeviation } \\
& \text { Voltage Deviation }=\sum_{\mathrm{i}=1}^{N p q}\left|\mathrm{~V}_{\mathrm{i}}-1\right| \\
& \mathrm{P}_{\mathrm{G}}=\mathrm{P}_{\mathrm{D}}+\mathrm{P}_{\mathrm{L}} \\
& \mathrm{P}_{\text {gslack }}^{\min } \leq \mathrm{P}_{\text {gslack }} \leq \mathrm{P}_{\text {gslack }}^{\max } \\
& \mathrm{Q}_{\mathrm{gi}}^{\min } \leq \mathrm{Q}_{\mathrm{gi}} \leq \mathrm{Q}_{\mathrm{gi}}^{\max }, \mathrm{i} \in \mathrm{N}_{\mathrm{g}} \\
& \mathrm{V}_{\mathrm{i}}^{\text {min }} \leq \mathrm{V}_{\mathrm{i}} \leq \mathrm{V}_{\mathrm{i}}^{\max }, \mathrm{i} \in \mathrm{N}^{\mathrm{max}} \\
& \mathrm{T}_{\mathrm{i}}^{\text {min }} \leq \mathrm{T}_{\mathrm{i}} \leq \mathrm{T}_{\mathrm{i}}^{\max }, \mathrm{i} \in \mathrm{N}_{\mathrm{T}} \\
& \mathrm{Q}_{\mathrm{c}}^{\text {min }} \leq \mathrm{Q}_{\mathrm{c}} \leq \mathrm{Q}_{\mathrm{C}}^{\max }, \mathrm{i} \in \mathrm{N}_{\mathrm{C}}
\end{aligned}
$$

\section{ENRICHED BLACK HOLE ALGORITHM}

In the black hole algorithm evolution of the population is through pushing the candidates in the course of the most excellent candidate in iterations and black hole which swap with those in the search space. Production of population is capricious and in the exploration space candidates, stars are present [17]. Incorporation of stars by the black hole is given as,

$$
\begin{aligned}
& Z_{i}(t+1)=Z_{i}(t)+\text { random } \times\left(Z_{B H}, Z_{i}(t)\right) i=1,2, \ldots, N \\
& H R=\frac{f_{b h}}{\sum_{i=1}^{N} f_{i}} \\
& Z_{i}=\left(s_{i}, \ldots, s_{N}, b h_{d}\right) \\
& G_{i j}^{d}=\xi\left(t_{o}\right) \frac{d_{p i}(t) \times d_{a j}(t) \times\left(s_{j}(t)-s_{i}(t)\right)}{\left(D_{i j}(t)+\varepsilon\right)^{2} \times\left(d_{p i}(t)+d_{a j}(t)\right)} \times\left(\frac{t_{o}}{t-t_{o}}\right)^{a} \\
& G_{i}^{d}(t)=\sum_{j=1}^{N} J \neq i \\
& r_{i} G_{i j}^{d}(t) \\
& m_{i}^{d}(t)=\frac{g_{i}^{d}(t)}{d_{i i}(t)} \\
& v_{e l o c i t y}^{d}(t+1)=r_{i} \times v_{i}^{d}(t)+m_{i}^{d}(t) \\
& s_{i}(t+1)=s_{i}(t)+v_{i}^{d}(t+1)
\end{aligned}
$$

With the steps as follows,

- Initialization

- Mutation and cross over are computed

- Position, velocity are calculated

- continued existence criterion calculated

- completion of Vector correction

- If maximum generation $\mathrm{g}_{\max }$ is attained, then stop, or else, go to Step b

In the proposed enriched black hole algorithm (EBHA) from the structure of the biological cell's membrane computing is planned by conceptual calculation of model from the hierarchy of the cells. Membrane computing is also branded as $\mathrm{P}$ system and it has multisets of objects with evolution rules in the membrane structure. Membrane structure is alike ingrained tree of section that demarcate the areas, and root is labelled as skin. Chemical substances (multisets of objects) are there inside the section (membranes) of a cell and the chemical reactions (evolution rules) that take place within the cell. 
Representation of membrane system as follows,

$$
\Pi_{B H}=\left(O_{B H}, \mu_{B H}, \omega_{B H}^{1}, \omega_{B H}^{2}, \ldots, \omega_{B h}^{i} \omega_{B H}^{q}, R_{B H}\right)
$$

Multi-set of the objects in every elementary membrane of the structure is given as,

$$
\omega_{i}=\left\{O_{1}, O_{2}, \ldots, O_{n}\right\}
$$

An object in -dimensional vector of the form given by,

$$
\begin{aligned}
& O_{j}=\left\{\left(Z_{11}, Z_{12}, \ldots, Z_{i d}\right), \ldots,\left(Z_{i 1}, Z_{i 2}, \ldots, Z_{i d}\right), \ldots,\left(Z_{k 1}, Z_{k 2}, \ldots, Z_{k d}\right)\right\} \\
& \left|\omega_{1} \cap \omega_{2} \cap \ldots \cap \omega_{i} \ldots \cap \omega_{q}\right| \leq \delta
\end{aligned}
$$

In the projected approach the fitness values of the objects are done by,

$$
\begin{aligned}
& F(X, Z)=\sum_{j=1}^{k} \sum_{i=1}^{m} W_{i j}\left\|X_{i}-Z_{j}\right\| \\
& Z_{i}(t+1)=Z_{i}(t)+r *\left(Z_{B H}-Z_{i}(t)\right)
\end{aligned}
$$

Radius of the event horizon is found by,

$$
H R=\frac{f_{B h}}{\sum_{i=1}^{n} f_{i}}
$$

With the steps as follows,

- Establish the elementary membrane numbers

- Initialize the population of stars for every elementary membrane, and choose the most excellent star

- Alter the location of every star

- Calculate the fitness of all stars for each elementary membrane again.

- In each elementary membrane, it will be swallowing by the black hole

- Until the end criterion is reached repeat the steps c to e.

- End

\section{SIMULATION RESULTS}

Enriched black hole algorithm (EBHA) validated in IEEE 14 and 300 bus systems [18]. Comparisons of results are presented in Tables 1 and 2. Graphical representation is shown in Figures 1 and 2.

Table 1. Comparison of loss

\begin{tabular}{llll}
\hline Parameters & ABCO [19] & IABCO [19] & EBHA \\
\hline V1 & 1.06 & 1.05 & 1.01 \\
V2 & 1.03 & 1.05 & 1.00 \\
V3 & 0.98 & 1.03 & 1.03 \\
V6 & 1.05 & 1.05 & 1.04 \\
V8 & 1.00 & 1.04 & 0.90 \\
Q9 & 0.139 & 0.132 & 0.100 \\
T56 & 0.979 & 0.960 & 0.900 \\
T47 & 0.950 & 0.950 & 0.900 \\
T49 & 1.014 & 1.007 & 1.000 \\
Power loss in MW & 5.92892 & 5.50031 & 4.0516 \\
\hline
\end{tabular}

Table 2 Comparison of power loss

\begin{tabular}{lllll}
\hline Parameter & EGA [21] & EEA [21] & CSA [20] & EBHA \\
\hline Power loss in MW & 646.299800 & 650.602700 & 635.894200 & 612.0914800 \\
\hline
\end{tabular}




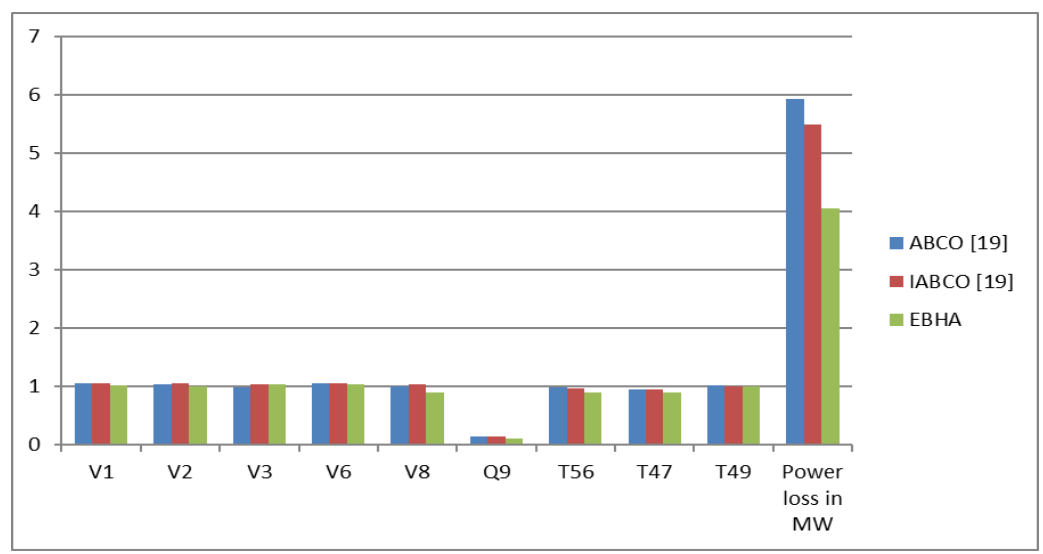

Figure 1. Comparison of parameters

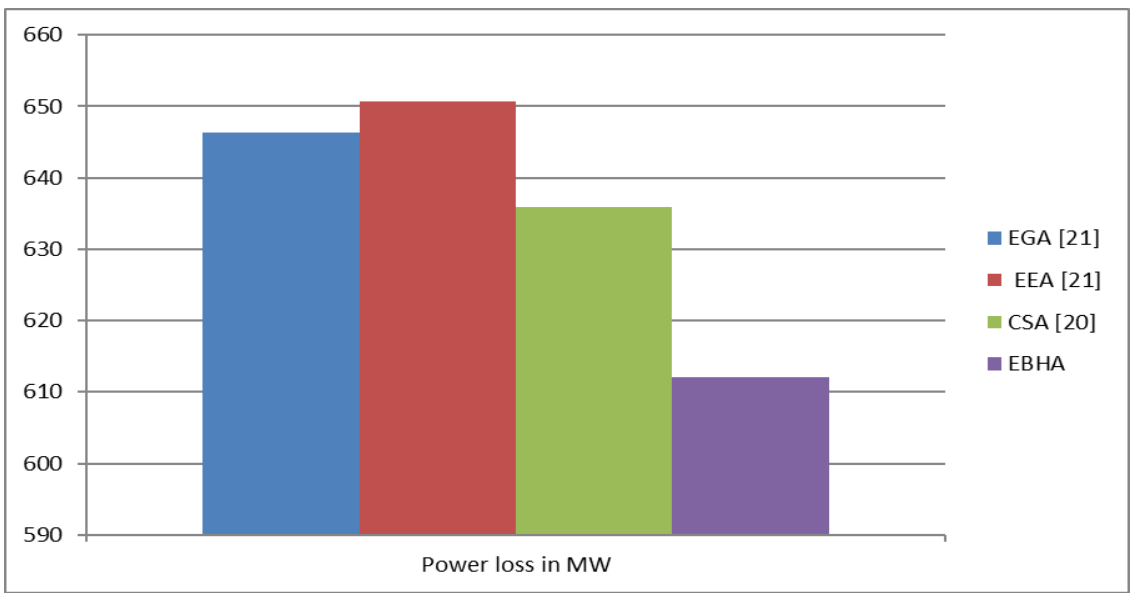

Figure 2. Comparision of power loss

\section{CONCLUSION}

Enriched black hole algorithm (EBHA) reduced the power loss effectively. Excellent candidate amongst all the candidates in iterations is chosen as a black hole and remaining candidates structured as the standard stars. From the structure of the biological cell's membrane computing is planned by conceptual calculation of model from the hierarchy of the cells. In IEEE 14 and 300 bus systems proposed enriched black hole algorithm (EBHA) performance has been validated. Power loss reduction has been achieved.

\section{REFERENCES}

[1] K. Y. Lee, "Fuel-cost minimisation for both real and reactive-power dispatches," Proceedings Generation, Transmission and Distribution Conference, vol. 131, no. 3, pp. 85-93, May 1984.

[2] N. I. Deeb, "An efficient technique for reactive power dispatch using a revised linear programming approach," Electric Power System Research, vol. 15, no. 2, pp. 121-134, Oct. 1988.

[3] M. R. Bjelogrlic, M. S. Calovic, and B. S. Babic, "Application of Newton's optimal power flow in voltage/reactive power control," IEEE Trans Power System, vol. 5, no. 4, pp. 1447-1454, 1990.

[4] S. Granville, "Optimal reactive dispatch through interior point methods," IEEE Transactions on Power System, vol. 9, no. 1, pp. 136-146, Feb. 1994.

[5] N. Grudini, "Reactive power optimization using successive quadratic programming method," IEEE Transactions on Power System, vol. 13, no. 4, pp. 1219-1225, Nov. 1998.

[6] Wei Yan, J. Yu, D. C. Y, and K. Bhattarai, "A new optimal reactive power flow model in rectangular form and its solution by predictor corrector primal dual interior point method," IEEE Trans. Pwr. Syst., vol. 21, no. 1, pp. 61-67, Jan. 2006.

[7] Aparajita Mukherjee and Vivekananda Mukherjee, "Solution of optimal reactive power dispatch by chaotic krill herd algorithm," IET Gener. Transm. Distrib., vol. 9, no. 15, pp. 2351-2362, Nov. 2015. 
[8] Hu, Z., Wang, X. and Taylor, "Stochastic optimal reactive power dispatch: Formulation and solution method". Electr. Power Energy Syst., vol. 32, no. 6, pp. 615-621, Jul. 2010.

[9] Mahaletchumi A. P. Morgan, et al., "Multi-objective evolutionary programming (MOEP) using mutation based on adaptive mutation operator (AMO) applied for optimal reactive power dispatch," ARPN Journal of Engineering and Applied Sciences, vol. 11, no. 14, Jan. 2016.

[10] Pandiarajan, K. and Babulal, C. K., "Fuzzy harmony search algorithm based optimal power flow for power system security enhancement," International Journal Electric Power Energy Syst., vol. 78, pp. 72-79, Jun. 2016.

[11] Mahaletchumi Morgan, et al., "Benchmark studies on optimal reactive power dispatch (ORPD) based multiobjective evolutionary programming (MOEP) using mutation based on adaptive mutation adapter (AMO) and polynomial mutation operator (PMO)," Journal of Electrical Systems, 2016.

[12] Rebecca Ng Shin Mei, et al., "Ant lion optimizer for optimal reactive power dispatch solution," Journal of Electrical Systems, Jan. 2015.

[13] Gagliano A. and Nocera F., "Analysis of the performances of electric energy storage in residential applications," International Journal of Heat and Technology, vol. 35, no. 1, pp. S41-S48, Sep. 2017.

[14] Caldera M., et al., "Survey-based analysis of the electrical energy demand in Italian households, Mathematical Modelling of Engineering Problems," vol. 5, no. 3, pp. 217-224, 2018, doi: 10.18280/mmep.050313.

[15] M. Basu, "Quasi-oppositional differential evolution for optimal reactive power dispatch," Electrical Power and Energy Systems, vol. 78, pp. 29-40, Jun. 2016.

[16] T. Weise, "Global Optimization Algorithms - Theory and Application," Germany: it-weise.de (self-published), 2009. [Online]. Available at: http://www.it-weise.de/.

[17] A. A. Heidari and R. A. Abbaspour, "Improved black hole algorithm for efficient low observable UCAV path planning in constrained aerospace," ACSIJ Advances in Computer Science: an International Journal, vol. 3, no. 3, May 2014.

[18] IEEE, "The IEEE-test systems," IEEE, 1993. [Online]. Available: http://www.ee.washington.edu/trsearch/pstca/.

[19] Chandragupta Mauryan Kuppamuthu Sivalingam, et al., "Reactive power optimization in a power system network through metaheuristic algorithms," Turkish Journal of Electrical Engineering \& Computer Science, vol. 25, no. 6, pp. 4615-4623, Jan. 2017.

[20] S. Surender Reddy, "Optimal reactive power scheduling using cuckoo search algorithm," International Journal of Electrical and Computer Engineering, vol. 7, no. 5, pp. 2349-2356, Oct 2017.

[21] S. S. Reddy, et al., "Faster evolutionary algorithm based optimal power flow using incremental variables," Electrical Power and Energy Systems, vol. 54, pp. 198-210, Jan. 2014. 